\title{
An Introduction to the Current State of HIV Vaccine Research
}

\section{Marc HV Van Regenmortel*}

Institut de Recherche de l'Ecole de Biotechnologie de Strasbourg (IREBS), Université de Strasbourg, France

Since 1987, more than 30 candidate HIV-1 vaccines have advanced to human clinical trials, of which some were large-scale phase IIb and III trials [1-3]. Of all these trials, only the Thai Phase III RV144 trial, based on a recombinant canarypox-HIV vector prime and recombinant HIV-1 envelope gp120 subunit protein, showed modest protection against HIV-1 infection [4]. This result came as a surprise because the RV144 trial, which had initially been fiercely condemned as illconceived and unjustified [5-7], instilled a new feeling of optimism into the field, because it suggested that developing a preventive HIV-1 vaccine may after all be feasible. Three years later, it seems appropriate to devote a special issue of the Journal of AIDS and Clinical Research to review what progress has been made in the search for a preventive HIV-1 vaccine.

The first contribution by Leopold Kong and Quentin Sattentau, entitled "Antigenicity and immunogenicity in HIV-1 antibody-based vaccine design", reviews in considerable detail the many studies aimed at developing an HIV-1 preventive vaccine by rational, structure-based design. This strategy, also known as reverse vaccinology [8,9], attempts to generate a vaccine from the crystallographic structure of broadly neutralizing monoclonal antibodies (bnMabs) bound to epitopes of the HIV-1 envelope (Env) glycoprotein.

These studies were initiated because of the availability of a small number of Mabs that recognize five different antigenic sites of the Env protein, i.e. the conserved CD4-binding site [10], the CD4-induced antigenic site that becomes accessible after Env interacts with the CD4 receptor [11], the semi-conserved V3 loop [12], the membrane-proximal external region of the gp41 protein [13] and the glycan antigenic site [14]. In subsequent years, many additional bnMabs directed to Env epitopes were isolated from HIV-1 infected persons [15-17] and had their structures elucidated by X-ray crystallography [18-22]. These bnMabs were then used as templates to reconstruct one of the epitopes that such Mabs are able to recognize using structure-based design technology. It was assumed that such reconstructed epitopes designed to fit bnMabs outside of the context of the Env antigen would possess the immunogenic capacity of inducing a neutralizing polyclonal antibody response in immunized hosts. When this was found not to be the case, attempts were made to improve the antigenic reactivity of the epitopes recognized by bnMabs using various strategies, such as adding flanking residues to the epitopes, constraining them in various conformations [23] and grafting them into various protein scaffolds [24-26].

Although some of these approaches increased the ability of the engineered epitopes to bind the bnMabs, none of these epitopes were found to be effective immunogens able to induce bnAbs [27-29].

In their discussion of these results, Kong and Sattentau suggest that the failure of the engineered epitope mimics to elicit broadly neutralizing antibodies could be due to their insufficient immunodominance, to an inadequate mimicry of the tertiary and quaternary structure present in native Env or because the epitopes possessed a low affinity for the germline B cell receptors (BCRs) present in the immunized hosts. They also stressed the basic quantitative/qualitative divide that separates the chemical description of an antigen and its biological effect on immunity. Although antigenicity can be reduced to the chemical level of an interaction between an epitope and a paratope, such a reduction is not feasible for immunogenicity which is a biological property determined mainly by the context of the host being immunized, namely its Ig gene repertoire and numerous cellular and regulatory mechanisms extrinsic to the immunizing epitope [30]. These host factors cannot be controlled when one uses as immunogen, an HIV-1 epitope designed to fit a particular bnMab since antigenic reactivity is not necessarily accompanied by the immunogenic capacity to elicit the same type of neutralizing antibodies.

The second contribution by Jason Okulicz is entitled "Elite controllers and long-term nonprogressors: models in HIV vaccine development". It reviews the characteristics of these two groups of HIVinfected individuals and discusses the issues related to their potential use as models for HIV vaccine design. Elite controllers are a very small subset of HIV-infected persons who control plasma viral load in the absence of antiretroviral therapy (ART). Long-term nonprogressors (LTNP) are somewhat more common and showed a prolonged elevation in CD4+ cell counts in the absence of ART [31]. Both elite controllers and LTNPs exhibit a high degree of heterogeneity with respect to host genetics, immunologic characteristics, rates of HIV disease progression and clinical outcomes. Although each of these two phenotypes present characteristics which one would like a vaccine to induce, i.e. virologic suppression and elevated CD4+ cell counts for prolonged periods, we unfortunately do not know how to elicit such responses by vaccination [32].

The third contribution by Hioe et al. and her coworkers from the New-York Langone Medical Center is entitled: "Targeting a neutralizing epitope of HIV envelope gp120 by immune complex vaccine". It has been known for many years that immunization with antigen-antibody complexes, instead of with antigen alone, can either up or down regulate the antibody response, although the precise mechanisms of these effects are poorly understood. Suppression of antibody responses may occur through the masking of epitopes or through the elimination of immune complexes by receptormediated phagocytosis. Enhancement on the other hand could result from specific Fc receptor targeting or from antibody-induced conformational changes in the antigen that exposes previously hidden epitopes [33]. Vaccines based on immune complexes have been found for instance to enhance the immune response to hepatitis $B$ antigens in humans [34] as well as to various viral infections in animals [35]. The Hioe group immunized mice wih immune complexes of HIV Env bound to human Mabs directed to the CD4-

*Corresponding author: Marc HV Van Regenmortel, CNRS, UMR7242 - Institut de Recherche de l'Ecole de Biotechnologie de Strasbourg (IREBS), Université de Strasbourg, Illkirch 67400, France, E-mail: vanregen@unistra.fr

Received May 17, 2012; Accepted May 21, 2012; Published May 24, 2012

Citation: Van Regenmortel MHV (2012) An Introduction to the Current State of HIV Vaccine Research. J AIDS Clinic Res S8:e001. doi:10.4172/2155-6113.S8-e001

Copyright: ( 2012 Van Regenmortel MHV. This is an open-access article distributed under the terms of the Creative Commons Attribution License, which permits unrestricted use, distribution, and reproduction in any medium, provided the original author and source are credited. 
binding site and observed enhanced neutralization Ab titers to Env and to the V3 loop compared to titers obtained by immunization with Env alone [36-38]. However, the mice did not produce Abs to the CD4bs because that site was blocked by the Mabs used to form the complexes. Since human IgG1 Mabs were used to form the complexes whereas the immunization experiments were done in mice, it will be important to confirm these results by small scale phase I trials in humans for human IgG1 Fc does not have the same affinity for murine and for human $\mathrm{Fc}$ receptors. It was also found that immune complexes, formed when an Env mutant lacking a glycan at position 448 in the $\mathrm{C} 4$ region was bound to an anti-CD4bs Mab, were able to elicit higher levels of neutralizing anti-V3 Abs than immunization with wild type Env complexes.

In their review the authors suggest that several mechanisms could be responsible for the enhanced immunogenicity of the immune complexes involving CD4bs Mabs, for instance an increased accessibility of the V3 epitopes, an increased resistance of gp 120 against degradation by proteases or a modulation of CD4+ T cell responses to various Env epitopes. Experiments are currently in progress to determine whether a regimen consisting of DNA priming/protein boost with immune complexes could further improve the immunogenicity of HIV neutralization epitopes.

The fourth contribution by Ray Greek entitled: "Animal models and the development of an HIV vaccine" discusses the experimental evidence that animal models used for studying HIV vaccine responses are not suitable for predicting what the response will be in humans. This is a controversial issue because policy makers and funding bodies continue to demand that nonhuman primate (NHP) models should be used in HIV vaccine research as predictors of human responses in spite of the fact that there is now good evidence that these models have no predictive value [39-42]. Showing protection in NHPs is no longer accepted as a gatekeeper for advancing a vaccine product into human efficacy trials since a product that works in macaques may not work in humans while a product that shows no efficacy in NHPs could nevertheless work in humans. Unfortunately, strategies that do not work in NHPs are not tested in humans with the result that potentially efficacious vaccines may have been lost.

If NHPs are not predictive, results with less closely related species such as mice and rabbits are of course even less likely to predict human responses. The review provides an exhaustive list of 224 references to back its numerous claims. It is well-known, for instance, that chimpanzees do not develop AIDS when infected with HIV-1 and that the pathology and immune responses observed in monkeys infected with simian immunodeficiency virus (SIV) and simian-HIV virus (SHIV) differ from what is observed with HIV infection. Statistical procedures used to calculate the positive predictive value of a vaccine intervention are described and the values that are obtained clearly demonstrate that NHP models are not a predictive modality. The last section of the review analyzes the complexity of biological systems and organisms that share a fairly recent common ancestor (such as monkeys and humans) and explains why small differences in gene interactions and regulatory networks can result in vastly different outcomes to the same immune system perturbation. The take home message is that: "When it comes to testing HIV vaccines, only humans will do" [43] which implies that currently used inter-species extrapolations should be abandoned and replaced by small scale human trials to test the safety and efficacy of candidate vaccine immunogens.

The fifth contribution from Stefano Butto and his group at the Institute of Health in Rome is entitled: "Characterization of variable regions of the gp120 protein from HIV-1 subtype C virus variants obtained from individuals at different disease stages in Sub-Saharan Africa". In this study, the authors tested the hypothesis that the selection of virus variants during the course of disease is caused by changes in the sequence characteristics of variable regions of the HIV Env protein. They examined HIV-1 clade C-infected individuals, naïve for antiretroviral therapy, at different disease stages, in order to characterize the V1 to V5 variable regions with respect to sequence length, glycosylation pattern and net electric charge. In the chronic stage of the disease, they observed in the V1, V2 and V4 loops, an increase in sequence length, amino acid variability and putative $\mathrm{N}$-glycosylation sites but very little change in the V3 loop as reported previously for clade C [44]. These data suggest that the V1 and V4 loops are likely to be the main drivers of clade C HIV-1 virus evolution which agrees with the finding that the V4 loop is a major target of neutralization activity in clade $\mathrm{C}$ infections [45].

The last contribution by Rachel Lai and Jonathan Heeney, entitled: "Perspectives in HIV vaccine development: what we have learned and how we proceed forward" reviews the advances made in HIV vaccine development in the context of the overall failure so far to develop a protective vaccine. Both $\mathrm{T}$ cell-based and antibody-based vaccine strategies are discussed and the limitations of reverse vaccinology are underlined. It is indeed often overlooked that all anti-HIV-1 bnMabs are polyspecific and harbor numerous binding sites capable of binding viral epitopes different from the one identified when the structure of bnMab-HIV-1 complex was solved [29]. There is therefore no reason why the HIV-1 epitope identified by crystallography should be the one that triggered the immune response that gave rise to the bnMab. Furthermore, the antigenic capacity of an epitope to bind to an $\mathrm{Ab}$ does not necessarily entail that the epitope also possesses the immunogenic capacity to induce that $\mathrm{Ab}$ in an immunized host [29]. In addition, since somatic hypermutation of germline BCRs leading to antibody affinity maturation is required to obtain bnAbs $[46,47]$, it seems unlikely that epitopes selected because they fit hypermutated bnMabs will be successful vaccine immunogens since the corresponding affinitymatured BCRs are not present in naïve, vaccinated individuals.

Calls for a greater focus on basic and preclinical research in immunology are often made because of the belief that this will provide the knowledge needed to guide the design of an effective HIV-1 vaccine $[3,48]$. Basic research may indeed give us an understanding of how an immune response sometimes arises in certain HIV-1 infected persons but whether this knowledge will bring us closer to the applied research goal of developing an effective vaccine remains an open question. It may therefore be wise to continue with exploratory early phase human trials testing a variety of immunization strategies [40] rather than waiting until we more fully understand all the intricacies of various types of immune responses to HIV-1 infection.

\section{References}

1. Mascola JR, Montefiori DC (2010) The role of antibodies in HIV vaccines. Annu Rev Immunol 28: 413-444.

2. McElrath MJ, Haynes BF (2010) Induction of immunity to human immunodeficiency virus type-1 by vaccination. Immunity $33: 542-554$.

3. Virgin HW, Walker BD (2010) Immunology and the elusive AIDS vaccine. Nature 464: 224-231.

4. Rerks-Ngarm S, Pitisuttithum P, Nitayaphan S, Kaewkungwal J, Chiu J, et al (2009) Vaccination with ALVAC and AIDSVAX to prevent HIV-1 infection in Thailand. N Engl J Med 361: 2209-2220.

5. Burton DR, Desrosiers RC, Doms RW, Feinberg MB, Gallo RC, et al. (2004) Public health. A sound rationale needed for phase III HIV-1 vaccine trials. Science 303: 316. 
Citation: Van Regenmortel MHV (2012) An Introduction to the Current State of HIV Vaccine Research. J AIDS Clinic Res S8:e001. doi:10.4172/2155-6113. S8-e001

6. Belshe R, Franchini G, Girard MP, Gotch F, Kaleebu P, et al. (2004) Support for the RV144 HIV vaccine trial. Science 305: 177-180.

7. Jefferys R, Harrington M (2004) Outstanding questions on HIV vaccine trial. Science 305: 180.

8. Burton DR (2002) Antibodies, viruses and vaccines. Nat Rev Immunol 2: 706713

9. Walker LM, Burton DR (2010) Rational antibody-based HIV-1 vaccine design: current approaches and future directions. Curr Opin Immunol 22: 358-366.

10. Kwong PD, Wyatt R, Robinson J, Sweet RW, Sodroski J, et al. (1998) Structure of an HIV gp120 envelope glycoprotein in complex with the CD4 receptor and a neutralizing human antibody. Nature 393: 648-659.

11. Labrijn AF, Poignard P, Raja A, Zwick MB, Delgado K, et al. (2003) Access of antibody molecules to the conserved coreceptor binding site on glycoprotein gp120 is sterically restricted on primary human immunodeficiency virus type 1 . J Virol 77: 10557-10565.

12. Zolla-Pazner S (2004) Identifying epitopes of HIV-1 that induce protective antibodies. Nat Rev Immunol 4: 199-210.

13. Zwick MB (2005) The membrane-proximal external region of HIV-1 gp41: a vaccine target worth exploring. AIDS 19: 1725-1737.

14. Scanlan CN, Pantophlet R, Wormald MR, Ollmann Saphire E, Stanfield R, et al. (2002) The broadly neutralizing anti-human immunodeficiency virus type 1 antibody $2 \mathrm{G} 12$ recognizes a cluster of alpha1-->2 mannose residues on the outer face of gp120. J Virol 76: 7306-7321.

15. Scheid JF, Mouquet H, Feldhahn N, Seaman MS, Velinzon K, et al. (2009) Broad diversity of neutralizing antibodies isolated from memory $B$ cells in HIV infected individuals. Nature 458: 636-640.

16. Simek MD, Rida W, Priddy FH, Pung P, Carrow E, et al. (2009) Human immunodeficiency virus type 1 elite neutralizers: individuals with broad and potent neutralizing activity identified by using a high throughput neutralization assay together with an analytical selection algorithm. J Virol 83: 7337-7348.

17. Stamatatos L, Morris L, Burton DR, Mascola JR (2009) Neutralizing antibodies generated during natural HIV-1 infection: good news for an HIV-1 vaccine? Nat Med 15: 866-870.

18. Zhou T, Xu L, Dey B, Hessell AJ, Van Ryk D, et al. (2007) Structural definition of a conserved neutralization epitope on HIV-1 gp120. Nature 445: 732-737.

19. Pancera M, McLellan JS, Wu X, Zhu J, Changela A, et al. (2010) Crysta structure of PG16 and chimeric dissection with somatically related PG9: structure-function analysis of two quaternary-specific antibodies that effectively neutralize HIV-1. J Virol 84: 8098-8110.

20. Changela A, Wu X, Yang Y, Zhang B, Zhu J, et al. (2011) Crystal structure of human antibody 2909 reveals conserved features of quaternary structurespecific antibodies that potently neutralize HIV-1. J Virol 85: 2524-2535.

21. McLellan JS, Pancera M, Carrico C, Gorman J, Julien JP, et al. (2011) Structure of HIV-1 gp120 V1/N2 domain with broadly neutralizing antibody PG9. Nature 480: 336-343.

22. Kim M, Sun ZY, Rand KD, Shi X, Song L, et al. (2011) Antibody mechanics on a membrane-bound HIV segment essential for GP41-targeted viral neutralization. Nat Struct Mol Biol 18: 1235-1243.

23. Ho J, Uger RA, Zwick MB, Luscher MA, Barber BH, et al. (2005) Conformationa constraints imposed on a pan-neutralizing HIV-1 antibody epitope result in increased antigenicity but not neutralizing response. Vaccine 23: 1559-1573.

24. Burton DR (2010) Scaffolding to build a rational vaccine design strategy. Proc Natl Acad Sci U S A 107: 17859-17860.

25. Ofek G, Guenaga FJ, Schief WR, Skinner J, Baker D, et al. (2010) Elicitation of structure-specific antibodies by epitope scaffolds. Proc Natl Acad Sci U S A 107: 17880-17887.

26. Correia BE, Ban YE, Holmes MA, Xu H, Ellingson K, et al. (2010) Computational design of epitope-scaffolds allows induction of antibodies specific for a poorly immunogenic HIV vaccine epitope. Structure 18: 1116-1126.

27. Pejchal R, Walker LM, Stanfield RL, Phogat SK, Koff WC, et al. (2010) Structure and function of broadly reactive antibody $\mathrm{PG} 16$ reveal an $\mathrm{H} 3$ subdomain that mediates potent neutralization of HIV-1. Proc Natl Acad Sci U S A 107: 1148311488.
28. Guenaga J, Dosenovic P, Ofek G, Baker D, SchiefWR, etal. (2011) Heterologous epitope-scaffold prime: boosting immunofocuses B cell responses to the HIV-1 gp41 2F5 neutralization determinant. PLoS One 6: e16074.

29. Van Regenmortel MH (2012) Requirements for empirical immunogenicity trials, rather than structure-based design, for developing an effective HIV vaccine. Arch Virol 157: 1-20

30. Van Regenmortel MH (2004) Reductionism and complexity in molecular biology. Scientists now have the tools to unravel biological and overcome the limitations of reductionism. EMBO Rep 5: 1016-1020.

31. Okulicz JF, Marconi VC, Landrum ML, Wegner S, Weintrob A, et al. (2009) Clinical outcomes of elite controllers, viremic controllers, and long-term nonprogressors in the US Department of Defense HIV natural history study. J Infect Dis 200: 1714-1723.

32. Migueles SA, Connors M (2010) Long-term nonprogressive disease among untreated HIV-infected individuals: clinical implications of understanding immune control of HIV. JAMA 304: 194-201.

33. Heyman B (1990) The immune complex: possible ways of regulating the antibody response. Immunol Today 11: 310-313.

34. Xu DZ, Zhao K, Guo LM, Chen XY, Wang HF, et al. (2008) A randomized controlled phase II $\mathrm{b}$ trial of antigen-antibody immunogenic complex therapeutic vaccine in chronic hepatitis B patients. PLoS One 3: e2565.

35. Roic B, Cajavec S, Ergotic N, Lipej Z, Madic J, et al. (2006) Immune complexbased vaccine for pig protection against parvovirus. J Vet Med B Infect Dis Vet Public Health 53: 17-23.

36. Visciano ML, Tuen M, Gorny MK, Hioe CE (2008) In vivo alteration of humora responses to HIV-1 envelope glycoprotein gp120 by antibodies to the CD4binding site of gp120. Virology 372: 409-420.

37. Hioe CE, Visciano ML, Kumar R, Liu J, Mack EA, et al. (2009) The use of immune complex vaccines to enhance antibody responses against neutralizing epitopes on HIV-1 envelope gp120. Vaccine 28: 352-360.

38. Kumar R, Tuen M, Li H, Tse DB, Hioe CE (2011) Improving immunogenicity of HIV-1 envelope gp120 by glycan removal and immune complex formation. Vaccine 29: 9064-9074.

39. Watkins DI, Burton DR, Kallas EG, Moore JP, Koff WC (2008) Nonhuman primate models and the failure of the Merck HIV-1 vaccine in humans. Nat Med 14: 617-621.

40. Thomas C (2009) Roadblocks in HIV research: five questions. Nat Med 15 855-859.

41. Shedlock DJ, Silvestri G, Weiner DB (2009) Monkeying around with HIV vaccines: using rhesus macaques to define 'gatekeepers' for clinical trials. Nat Rev Immunol 9: 717-728.

42. Corey L, Nabel GJ, Dieffenbach C, Gilbert P, Haynes BF, et al. (2011) HIV-1 vaccines and adaptive trial designs. Sci Transl Med 3: 79ps13.

43. Tonks A (2007) Quest for the AIDS vaccine. BMJ 334: 1346-1348.

44. Patel MB, Hoffman NG, Swanstrom R (2008) Subtype-specific conformational differences within the $V 3$ region of subtype $B$ and subtype $C$ human immunodeficiency virus type 1 Env proteins. J Virol 82: 903-916.

45. Moore PL, Gray ES, Choge IA, Ranchobe N, Mlisana K, et al. (2008) The c3-v4 region is a major target of autologous neutralizing antibodies in human immunodeficiency virus type 1 subtype C infection. J Virol 82: 1860-1869.

46. Gray ES, Madiga MC, Hermanus T, Moore PL, Wibmer CK, et al. (2011) The neutralization breadth of HIV-1 develops incrementally over four years and is associated with CD4+ T cell decline and high viral load during acute infection. J Virol 85: 4828-4840.

47. Chen W, Streaker ED, Russ DE, Feng Y, Prabakaran P, et al. (2012) Characterization of germline antibody libraries from human umbilical cord blood and selection of monoclonal antibodies to viral envelope glycoproteins: Implications for mechanisms of immune evasion and design of vaccine immunogens. Biochem Biophys Res Commun 417: 1164-1169.

48. Fauci AS, Johnston MI, Dieffenbach CW, Burton DR, Hammer SM, et al. (2008) HIV vaccine research: the way forward. Science 321: 530-532. 